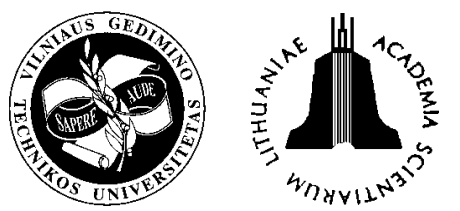

\title{
DEVELOPMENT OF INTERMODAL TRANSPORT IN NEW EUROPEAN UNION STATES
}

\author{
Algirdas Šakalys, Ramūnas Palšaitis \\ Transport Research Institute, Vilnius Gediminas Technical University, \\ Plytinés g. 27, LT-10105 Vilnius, Lithuania, e-mail: algirs@ti.vtu.lt \\ Received 5 March 2006; accepted 28 March 2006
}

\begin{abstract}
The article presents the main outcomes of the NAS-ITIP project (FRAMEWORK'5) on the situation of intermodal transport in new European Union states. The main measures for the development of intermodal transport in these countries are highlighted: modernisation and development of intermodal infrastructure; innovative technologies; establishment of modern logistics centres. Recommendations to EC and national governmental institutions for the development of intermodality are proposed.
\end{abstract}

Keywords: intermodal transport; innovative technologies, logistics centres; motorways of the sea.

\section{Indroduction}

After NAS-ITIP project investigations it became evident that all governments of new associated European Union countries (NAS countries) have to multiply objectives and efforts in pursuing their transport policies.

NAS countries are intended to develop and reform a transport sector considering their national needs, as well as taking into account the main trends of the European Union transport policy. It is clear that the ranking of transport development objectives continues to change in the light of significant technological development, further liberalisation of transport market, expanding globalisation of trade, and growing environmental concerns. On the European wide level the objectives of a transport sector continue adoption and changes considering the new demands. The European Union must accurately evaluate them and move towards substantial changes in Common European Transport Policy (CETP). Europe faces new objectives for transport development, such as restoring of the balance between the modes of transport and developing of intermodality, combating congestion, putting safety and quality of services on the top of efforts of transport companies as well as public institutions. The Transport White Paper adopted by European Commission on 12 September 2001 draws a realistic picture of recent years transport situation and sets out an ambitious action programme comprising more than 60 different measures which are foreseen to be implemented till 2010. The task "turning intermodality into reality" is one of the basic issues and one of the main measures of development of CETP presented in the White Paper [1]. The priorities must be taken to ensure complete integration of different transport modes, as well as technical harmonisation and interoperability between infrastructure and operational systems, particularly for containers. NAS-ITIP project was elaborated in order to support European Commission policy in the development of intermodality. As it was expected from the beginning, NAS-ITIP project findings could be useful in the process of "implementation intermodality into reality" in new EU member states.

Analysing NAS transport policy development plans and strategies we found that the basic objective of intermodality development is to achieve that transport of NAS countries, being a part of the integrated EU transport system:

- could be in line with EU standards level according to its technical parameters and quality services;

- would effectively interact with the transport systems of the neighbouring countries;

- would effectively serve national as well as common interest of enlarged EU and increase EU competitive potential in the international markets. During NAS-ITIP project research stage the main measures in NAS for the achievement of the above mentioned tasks were highlighted. Among them: modernization and development of intermodal 
infrastructure, as well as promotion of intermodal transport processes and innovative technologies, which allow to increase the efficiency of transport and logistics operations and at the same time stipulate the reduction of a negative impact of transport on the environment.

\section{The role of intermodal transport in NAS countries}

The project analysis proved that the average share of intermodal transport in relation to the total transport market in new member states is on a rather low level.

The market analysis focused on the situation of intermodality and especially on the transfer points in the intermodal transport in new member states. On the basis of this analysis the following main issues on the intermodal transport markets in NAS countries can be concluded:

- the market share of intermodal freight transport using railway transport on the main leg is very small and amounted to $1,1-1,5 \%$ in average for the member states. Only in Hungary that share is much higher and amounted to $12 \%$, which is comparable to an average European level. Intermodal transport in inland waterway is being used at present only in the Czech Republic, with a share of $0,2 \%$ of the total traffic. The share of ITU transported by short sea shipping amounts to $9,5-30 \%$ (Poland and Lithuania respectively);

- international intermodal transport has an absolutely dominant position in total intermodal markets in new member states with a share of 80$90 \%$ an average. International intermodal transport is carried out along the main railway lines (covering by AGTC agreement) as well as within Pan-European Transport Corridors;

- as far as the structure of ITU is concerned, the transportation of containers with shares of 80$90 \%$ an average has a dominant position. The shares of swap bodies and semi-trailers amounted to $14-20 \%$ an average. Only in the countries where Ro-La technology is used, the share of trailers is relatively higher.

NAS-ITIP identified as the main reasons for the low market share of intermodal transport in new member states:

- a strong competitive position of road transport in the markets;

- $\quad$ still a low quality of railway services provided within intermodal transport chains;

- too high railways rates in spite of a low service quality;

- still a non-satisfactory quality level of railway infrastructure (in most of NAS countries), resulted from the fact that the most financial sources are allocated to the construction and modernisation of road network;

- insufficient government support for the development of intermodal transport, both in terms of administrative and financial promotion instruments. There is a discrepancy between the principle of political support for sustainable transport development - with focus on shifting goods from road to rail, and real actions aiming to establish such mode shift on the other side [2].

The analysis of the technological development in intermodal transport and the level of technical interoperability in new member states leads to the common conclusions that there are three basic types of technologies in use: Lo-Lo (the most widespread), Ro-Ro and Ro-La. Ro-Ro systems are most frequently operative at sea ports. Ro-La services are especially developed in Hungary, and some of them are also offered in Poland and Romania. A few innovative or new technologies were developed and employed in new member states, i.e:

- a system of road - rail horizontal transshipment (Poland, the Czech Republic);

- horizontal cargo transshipping machine (Hungary);

- SUW 2000 -automatic wheel-gauge changing system (Poland, Lithuania);

- new comprehensive IT technologies at some intermodal terminals of NAS countries. With a few exceptions, the technologies used are regarded as conventional (Western) technology. From the background of close-up process in the member states the means of the development of intermodal transport concepts concentrate their efforts on creating a basis for intermodal transport rather than on the development of innovative concepts on transshipment technologies.

The status of being a new member state puts the necessity on national as well as on EC policy to stimulate essential improvements in the development of integrated intermodal transport systems in these countries.

As a result of the enlarged EU, new member states have a dual role, i.e., they have functions as a part of the extended EU and also as a connecting chain with CIS and the Mediterranean countries.

According to the results of TINA studies carried out in process of planning TEN-T network (in new member states) a significant increase of traffic was forecasted in these countries. It was foreseen that until 2015 the volumes of export would amount to $90-150 \%$ and import - to 80-140 \% in comparison with 1998.

Current trends in a transport sector, such as the ongoing growth of volumes and hence the accompanying growth in transport, will lead to negative envi- 
ronmental and social effects. This therefore requires a change of strategy in Common Transport Policy in Europe (CETP) in promoting railway, short sea shipping, inland waterway transport and placing users at the centre of the system guaranteeing their right to efficient, safe, affordable, and environment-friendly transport. As a part of a framework for sustainable mobility, intermodality has been identified as a key issue requiring enhancement. The improvement of intermodality between old EU Member States and NAS will be an important contribution to the development of sustainable transport.

The increase of the volumes of traffic and especially the rapid growth of demand for intermodal transport reveals the problems of transport infrastructure capacity and quality in the main lines of TEN-T within new member states, as well as in the Pan-European Transport Corridors, connecting NAS with the third countries.

Political support for the development of intermodal transport is reflected in the national transport plans and strategies. By 2010-2015 in all countries concerned an essential increase in market share of intermodal transport is expected. Those plans include the increase and acceleration of the investment on transport infrastructure (first of all - AGTC railways lines), the establishment and development of intermodal terminals, modern logistics and transport centers ("freight villages"), as well as the introduction of promotion measures under national policies.

From NAS the following policy and research priorities for the development and improvement of the productivity of intermodal transport can be formulated:

1. Intermodal nodes as a part of TEN-T network and Pan-European Corridors: intermodal terminals and modern transport centres ("freight villages") have to be integrated into TEN-T network. At present, ports are included, but intermodal terminals and "freight villages" are still missing. They must be defined along with other new concept such as the motorways of the sea motorways. This topic includes three basic aspects:

- lack of basic knowledge of an intermodal terminal network on European level;

- there is no common view on financing intermodal terminals;

- intermodal terminals and "freight villages" are not directly connected to TEN-T network.

2. Organisational aspects in the logistics chainintegration of an actor: there is a need to address the organisational aspects in the logistics chain in order to integrate actors in a more effective manner by focussing on the market and adopting IT solutions for organisation and services.

3. Centralised information and data for information flows management: centralised information and data are needed because parties usually do can not manage the information flows over all business relationships included in intermodal transport chains.

A one-stop shop is needed for integrating intermodal terminals and "freight villages" into intermodal transport chains by harmonising interfaces, e.g. to administrative procedures and offering a set of information and communisation tools and services to ease data delivery to all partners in the chain (operators, clients and public authorities).

4. Presently intermodal transport infrastructure planning and development in TEN-T network and PanEuropean Transport Corridors are realised in accordance with a separate national interest. Meanwhile, the implementation of such projects should be focused not only following a national interest, but also in accordance with the common European interest. Therefore, there is a need for serious investigations and research in order to develop a methodology for the evaluation of a common European intermodal interest.

\section{Intermodal transport infrastructure development}

Intermodal transport infrastructure development, improvement of legislation and recommendations for state support for intermodal transport alongside with the above mentioned policy and research topics are also the key priorities. These priorities are the most important instrument a shaping the technical and organisational basis, and at the same time creating a favourable environment for intermodal transport development.

Transport networks are the arteries of the European Common Market and even more - market driving forces. Therefore, the development and upgrading of transport services and infrastructure is one of the essential issues ensuring the progress of economy, elaborating strategies and programmes for the whole European Community, as well as for all Member States of the European Union individually.

TEN-T network development plans are based upon the Treaty establishing the European Community of 25 March 1957 as amended on 2 October 1997 and the guidelines based upon this Treaty for the development of a Trans-European Transport Network of 23 July 1996.

According to TEN-T guidelines, the development and improvement of TEN-T network serve to fulfill important common goals such as the smooth operation of the single market and the reinforcement of economic and social cohesion. Following to Art. 154 of the Treaty, the Union shall help to achieve the goals of development and improvement of TEN-T networks. It shall be done by promoting the system and the access to these networks. This objective can only be 
achieved, if a necessary transport network is developed on the basis of standard parameters.

The new list of priority projects (including projects of NAS countries) of common Union interest was prepared by Karl van Miert High Level Group on TransEuropean Network last year and was approved by the EU institutions in the beginning of this year. The guidelines and a priority project list are the most important means of EU fulfilling its transport infrastructure task by developing and improving TEN-T network. Thoey are a legal basis, which specifies objectives, priorities and essential features of the activities of the European Union in the field of TEN-T network.

However, our findings after NAS-ITIP project investigations confirmed the fact that TEN-T and Pan-European Transport Corridors infrastructure projects of high European priority are being planned and realized first of all relying upon a national interest of each country involved in the process. In many cases countries face problems of harmonising national interests with the common ones, such as cases of Via-Baltica and Rail Baltica projects, which are currently implemented by the Baltic States and Poland. Problems arise in projects monitoring due the different level of the priorities countries are rendering to these mentioned projects. It is evident that intermodal transport infrastructure planning and development measures in the main TEN-T network and Pan-European Transport Corridors should be carried out according to the requirements of European trade and transport demands to benefit trade and competitiveness of common Europe.

Therefore, an essential issue of planning and implementing TEN-T network or the main axis projects is to determine an appropriate role for $\mathrm{Eu}$ ropean Commission and other EU institutions within the European Union. In other words - the coordination of common European interest infrastructure projects related to the development of intermodality, as well as Pan-European Corridors has to be institutionalized. The establishment of the post (institution) of the "European coordinator" is only the first important step towards facilitation of the coordinated implementation of the projects declared to be of European interest. Other important steps in this direction have to be done. The real implementation of Pan-European Transport Corridors Steering Committees' work results by the decision making structures of the EU and the Corridors related countries is very desired and important. Despite of the fact that Steering Committee's efforts in the intermodal transport development are based mostly on European economic prospective and on cooperation of the EU member states with the third countries, at present time in many cases outputs of the Corridors Committee's work do not receive the serious atten- tion from the above mentioned supranational and national institutions.

The harmonization of technical infrastructure parameters can contribute to the efficiency of TEN-T networks decisively. The identification of projects of common European interest as future TEN-T in the Central and Eastern European countries was performed in 1999 during preparation of TINA network. TINA network identifies an intermodal network of the main traffic routes in NAS countries. TINA network which needs modernisation totally covers $20000 \mathrm{~km}$ of rail track, $18000 \mathrm{~km}$ of road, $4000 \mathrm{~km}$ of waterway, 20 seaports, 58 river ports and 40 airports, as well as 40 intermodal terminals. The intermodal transport infrastructure in NAS countries commonly has considerable investment deficit. TINA network has investment needs of 91 billion Euro (seeking to achieve old EU member states TEN-T technical quality level). The improvement of this infrastructure, which is necessary anyway, represents the opportunity to lay down uniform technical infrastructure parameters, which should apply to all EU countries.

In no other transport sector do technical infrastructure parameters play such a crucial role as in the rail sector since numerous technical devices such as signalling, safety technologies and power supply are stationary installations on the particular track. And no other transport sector is so far away from standardising of these parameters. One of the greatest obstacles in cross-border rail traffic in NAS countries is the discrepancies in the technical infrastructure parameters of various national rail networks as for example between the Baltic States and Poland.

The standardisation of technical infrastructure parameters, signal and power supply systems is an urgent task. In the process of modernising these systems it should be focused on the introduction of a uniform safety system, which fulfils all the requirements of modern rail traffic, and which can be introduced in the medium - term as a general safety system in all railway infrastructure companies throughout Europe.

The incorporation of motorways of the sea to TEN-T network is also an important matter of intermodal transport development in NAS countries. The motorways of the sea concept aims at introducing new intermodal maritime based logistics chains in Europe, which should bring about a structural change in our transport organisation within the next years to come. The adoption of TEN-T network Guidelines of 29 April 2004 by the Council and the European Parliament gives a legal framework for funding the motorways of the sea, if such motorways development will be recognized having common interest for at least two EU member states [3].

But in search of ensuring success of the motorways of the sea projects it would be necessary 
to carry out comprehensive researche into potential freight flows and to achieve that all actors in the supply chain have to be committed to these projects. Virtually it is necessary on a research basis to develop further recommendations for the development of the motorways of the sea.

One of the priorities for the development of intermodal transport in new member states NAS (in which we see considerable reserves for larger cooperation among NAS counties and EU old Member States in transport research) is the formation of a network of intermodal transport centres ("freight villages") near TEN-T network and Pan-European Transport Corridors in industrial areas.

The model which could be used for the logistics centre size and location optimization is based on the following assumptions:

- the optimum location is chosen from a finite number of the candidate nodes;

- the model takes into account the relations between the transport costs and the centre costs (construction, maintenance, land cost, internal warehousing and handling costs etc.);

- the decision maker can determine the optimum location and the size of centres but cannot solve the problem of transport means allocation to transport tasks;

- it is assumed that transport means (e.g. trucks) optimize their routes choosing a logistics centre from the available ones.

The discussed model consists of decomposition of two interdependent levels - the upper and the lower level.

The objective function and constraints for the upper level problem have the following form:

$$
\begin{aligned}
& \min _{x \in X, y \in Y} T C(x, y)= \\
& \sum_{i} x_{i} C_{i}+\sum_{a} c_{t} t_{a} V_{a}+\sum_{i} x_{i} C^{\prime}{ }_{i}+\sum_{b} c^{\prime}{ }_{t} t_{b} V^{\prime}{ }_{b}
\end{aligned}
$$

with constraints:

$$
\begin{aligned}
& C_{i}=c_{b i} y_{i} T+c_{t} n_{y i}\left(q_{i}\right) T \quad \forall i, \\
& C_{i}^{\prime}{ }_{i}=c_{b i} y_{i}^{\prime} T+c^{\prime}{ }_{t} n_{y^{\prime} i}\left(q_{i}^{\prime}\right) T \quad \forall i, \\
& q_{i}=\sum_{o} q_{o i}+\sum_{d} q_{i d} \quad \forall i, \\
& q_{i}^{\prime}=\sum_{o} q_{o i}^{\prime}+\sum_{d} q_{i d}^{\prime} \quad \forall i, \\
& V_{b}^{\prime}=\sum_{i} \sum_{o} \delta_{b i} q_{i d}^{\prime}+\sum_{i} \sum_{d} \delta_{b i} q_{i d}^{\prime} \quad \forall b, \\
& \sum_{o} \alpha q_{o i}=\sum_{d} \alpha^{\prime} q_{i d}^{\prime} \quad \forall i, \\
& \sum_{d} \alpha q_{i d}=\sum_{o} \alpha^{\prime} q_{o i}^{\prime} \quad \forall i,
\end{aligned}
$$

where:

$x, y \quad$ - vectors representing the location and the number of reloading stands of potential logistics centres, respectively;

$X, Y \quad-x, y$ vector sets;

$x_{i} \quad$-zero-one variable ( $x_{i}=1$ if a centre is located in $i$ node, $x_{i}=0$ otherwise);

$C_{i}, C_{i}^{\prime} \quad$ - total cost of the alternative transport means service in centre $i$ in time $T$;

$c_{t}, c_{t}^{\prime} \quad-$ unit cost of transport by alternative means in centre $i$;

$t_{a}, t_{b}$ - transport time by alternative routes $a$ and $b$;

$V \quad$ - stream of vehicles (number of vehicles/time unit);

$V_{a}, V_{b}$ - streams of vehicles in alternative routes $a$ and $b$;

$c_{b i} \quad-$ cost per hour of stay on a reloading stand in centre $i$;

$y_{i}, y_{i}^{\prime} \quad$ - number of reloading stands for alternative transport means in centre $i$;

$T \quad$ - planning time;

$q_{i}, q_{i}^{\prime} \quad$ - numbers of alternative vehicle types visi-

$n_{y i}\left(q_{i}\right)$ - average number of vehicles in centre $i$, which has $y i$ reloading stands;

$q_{o i}, q_{o i}^{\prime}$ - flow of alternative vehicles from supplier o to centre $i$ (number of vehicles/time unit);

$q_{i d}, q_{i d}^{\prime}$-flow of alternative vehicles to receiver $\mathrm{d}$ from centre $i$ (number of vehicles/time unit);

$\delta_{b i} \quad$-zero-one variable ( $\delta_{b i}=1$ if transport between supplier o, centre $i$ and receiver $d$ is performed by route $\mathrm{b} ; \delta_{b i}=0$ otherwise);

$\alpha, \alpha_{i} \quad$ - cargo transported by alternative means of transport ( $\mathrm{t} /$ vehicle).

The objective function and constraints for the lower level take the following form, respectively:

$$
\min \sum_{\mathrm{a}} \int_{\mathrm{O}}^{\mathrm{V}_{\mathrm{a}}} t_{a}(V) d V-\sum_{o} \sum_{d} \int_{o}^{q_{o d}} W_{o d}(z) d z
$$

with constraints:

$$
\begin{aligned}
& f_{r, o d}=x_{i} f_{r, o d} \quad \forall r, o d, \\
& \sum_{r} f_{r, o d}=q_{o d} \forall o d, \\
& \sum_{r} f^{\prime \prime}{ }_{r, o d}=q^{\prime \prime}{ }_{o d} \quad \forall o d, \\
& V_{a}=\sum_{o} \sum_{d} \sum_{r} \delta_{r, a}^{o d} f_{r, o d}+\sum_{o} \sum_{d} \sum_{r} \delta_{r, a}^{o d} f^{\prime \prime}{ }_{r, o d} \quad \forall a, \\
& \sum_{o} q_{o d}=D_{d} \quad \forall d, \\
& \sum_{d} q_{o d}=O_{o} \quad \forall o, \\
& f_{r, o d} \geq 0 \quad \forall r, o d,
\end{aligned}
$$




$$
f^{\prime \prime}{ }_{r, o d} \geq 0 \quad \forall r, o d,
$$

where:

$W_{o d(z)} \quad$ - inverse demand function per vehicle stream; $o, d$ are candidate nodes for centre $i$;

$q_{o d}, q_{o d}^{\prime \prime}-$ stream of vehicles for $o, d$ pair (vehicles/ day);

$f r, o d, f^{\prime \prime} r, o d-$ stream of vehicles for path $r$ determined by $o, d$ pair;

$\delta_{r, a}^{o d} \quad$ - zero-one variable ( $\delta_{r, a}^{o d}=1$ if path $r$ crosses $a$ route, $\delta_{r, a}^{o d}=0$ otherwise);

$O_{o}, D_{d}$ - generation value for centroid $o$ and attraction value for centroid $d$ (vehicles/day).

The presented model is a two-level nonlinear programming problem, proposed an effective genetic solution algorithm for it [4].

The NeLoC study carried out in the frames of the Baltic Sea Region INTERREG III B programme illustrated that the development of an intermodal transport network will have positive effects on:

- the enhanced mobility of freight using efficiently various possibilities of interconnection between different transport modes;

- the quality of transport services;

- the creation of new permanent jobs;

- the efficient use of modern information and communication technology

- better business conditions for small and medium size transport companies.

\section{Conclusions}

The main recommendations for further development of intermodal transport in NAS countries were made following ITIP-NAS project investigations:

\section{The recommendations to $\mathrm{EC}$ :}

1. In order to incorporate the intermodal terminals and "freight villages" into TEN-T network start the preparation of the amendments to the Community guidelines for the development of trans-European network.

2. To initiate research work on the methodology and indicators for the evaluation of the common $\mathrm{Eu}-$ ropean interest in the development of intermodal transport on the basis of provisions Art. 19 and 19 a of the Decision No 884/2004/EC on Community quidelines for the development of trans-European transport network.

3. To iniciate special studies and research work in order to form a network of the motorways of the sea connecting concrete seaports and concrete intermodal inland TEN-T routes.

4. To iniciate studies and research work into plan- ning and development of modern intermodal logistics centres ("freight villages") in NAS counties area.

5 . To introduce an uniform licence for intermodal transport freight forwarders in all NAS and other EU countries.

6. Aiming to ensure a designated customer service level, to introduce technical planning requirements (and minimal distances from the residential areas) for the establishment of public intermodal transport terminals.

The recommendations to EC and NAS governmental institutions:

1. The Steering Committees of the Pan-European Transport Corridors have to be more actively included in the decision making processes of the European Union institutions, as well as in the decision making processes of the government institution of the intermodal Corridor countries.

2. To establish uniform standards for overall reliability, secure transit time and cargo security of public intermodal transport terminals in all EU countries.

3. To initiate the establishment of an obligatory standardised and harmonized regulation system of intermodal transport operations between EU and non EU countries.

The recommendations to NAS governmental institutions:

1. To prepare national plans for the development of intermodal transport.

2. In the process of preparation national or regional strategies and plans for the development of intermodal transport to include the means harmonizing administrative procedures offering a set of information and communication tools allowing efficiently to integrate intermodal terminals into intermodal transport chains.

3. To ensure financial support for the construction and reconstruction of combined and intermodal transport infrastructure facilities (to promote financing from structural and cohesion funds, to promote PPP).

\section{References}

1. White Paper. European transport policy for 2010: time to decide. Brussels, $\mathrm{COM}(2001)$.

2. Bazaras, D.; Palšaitis, R. Analysis of the Prospectives of Intermodal Transport and Logistics Centres in Lithuania. Transport, Vol XIX, No 3, 2004, p. 119-123.

3. Trans-European Transport Network. Revised proposals on guidelines and financial rules 2004 Luxemburg: Office for Official Publications of the European Communities, 2004.

4. Networking logistics centres in the Baltic sea region. NeLoC. Working Package 1. Planning of logistics centres. Gdansk 2003, Poland. 